\title{
Ventriculoperitoneal shunt catheter protrusion through the anus: case report of an uncommon complication and literature review
}

\author{
Volkan Etus
}

Received: 29 July 2011 /Accepted: 29 July 2011 /Published online: 9 August 2011

(C) Springer-Verlag 2011

In this report, Glatstein et al. have presented an 11-year-old girl with rectal protrusion of the ventriculoperitoneal (VP) shunt tube, and they have summarized the 23 cases of anal protrusion of VP shunt reported in the literature.

The most frequent $(45 \%)$ finding in delayed bowel perforation by VP shunt catheters is protrusion of the distal catheter from the anus [1]. In my opinion, this protrusion seems like a chance for the patient as it helps the early diagnosis of perforation as in the case presented herein.

The authors have also discussed the pathogenesis of delayed bowel perforation by VP shunt catheter. As the authors have indicated, children with myelomeningocele were reported to be more susceptible to bowel perforation, possibly due to their weaker bowel musculature [2]. In the literature, there are also several other explanations, which should have been emphasized in the report. One of those possible mechanisms was proposed by Brownlee et al. [3], and they suggested that allergic reaction to silicone might lead to adherence of shunt tubing to the intestinal wall with subsequent erosion into the lumen. In another report, Miserocchi et al. pointed out that the pathogenesis was most likely to be related with local infective adhesions of the bowel [4]. Among the reasons for protrusion of the VP catheter from the anus, trauma during the operation should also be taken into consideration. A minor trauma to the bowel may cause a local inflammation which may lead the bowel wall to become more susceptible to the mechanical irritation by the catheter tip. Today, the pathogenesis of delayed bowel perforation by VP shunt catheter is not clear yet. However, we may assume that there is more than one possible mechanism for delayed bowel perforation by VP shunt catheter.

\section{References}

1. Thipphavong S, Kellenberg CJ, Rutka JT, Manson DE (2004) Hepetic and colonic perforation by an abandoned ventriculoperitoneal shunt. Pediatr Radiol 34:750-752

2. Adeloye A (1997) Protrusion of ventriculoperitoneal shunt through the anus: report of two cases. East Afr Med J 74:337-339

3. Brownlee JD, Brodkey JS, Schaefer IK (1998) Colonic perforation by ventriculoperitoneal shunt tubing: a case of suspected silicone allergy. Surg Neurol 49:21-24

4. Miserocchi G, Sironi VA, Ravagnati L (1984) Anal protrusion as a complication of ventriculo-peritoneal shunt. Case report and review of the literature. J Neurosurg Sci 28:43-46
V. Etus $(\bowtie)$

Department of Neurosurgery, Faculty of Medicine,

Kocaeli University,

Umuttepe, 41380 Kocaeli, Turkey

e-mail: drvolkanetus@yahoo.com 